\title{
Examining the validity and reliability of the Greek version of the Bar-On's Emotional Quotient Inventory
}

\author{
Lefkios Neophytou \\ School of Education, University of Nicosia, \\ Cyprus
}

\begin{abstract}
:
This study examined the validity and reliability of the Greek version of the Bar-On's (1997) Emotional Quotient inventory. Participants in the study were 272 Cypriot adults (teachers and student teachers) aged 18-53. The internal reliability of the instrument was very high concerning the total scale and more than adequate for all its composite scales and subscales. The instrument's construct validity was examined by a combination of exploratory and confirmatory factor analysis. Exploratory factor analysis revealed a different factorial structure concerning the instrument's subscales from the structure suggested in the technical manual (35 instead of 15). Confirmatory factor analysis revealed that all goodness of fit indexes were gratified for all the EQ-i composite scales but not for the general-total scale of emotional intelligence. Overall, the results suggest that the EQ-i is a reliable instrument to be used across different population samples. Nevertheless, additional research is needed in order to establish the instruments' underlying theoretical structure.
\end{abstract}

Keywords: Emotional Intelligence, Measurement, Validation.

Corresponding author: Lefkios Neophytou

E-mail: neophytou.1@unic.ac.cy

Educational Research eJournal ISSN 2254-0385

(C) Faculty of Education. University of Alicante- Spain

DOI: 10.5838/erej.2012.12.04 


\section{Introduction}

\subsection{Emotional intelligence: definition and models}

Over the past twenty years, Emotional intelligence (EI) has become a major topic of growing scientific interest. Broadly, EI refers to abilities for identifying, processing and managing emotions in both others and oneself (Goleman, 1995; Mayer \& Salovey, 1997). As such, Emotional intelligence represents an attempt to complement the traditional view of intelligence by examining how certain emotional, personal, and social abilities, interact with cognition and contribute to intelligent behaviour (Gardner, 1983; Mayer \& Salovey, 1997).

Many models and definitions of EI coexist and compete one another. Mayer and his colleagues (Mayer, Salovey \& Caruso 2000; Mayer \& Ciarrochi, 2006) provided one of the most influential taxonomies regarding the models of EI. According to this taxonomy, all the different models of EI can be categorised into two groups: Ability models and Mixed models (also defined as Trait/personality models). Mixed models (i.e. Bar-On, 1997; Goleman, 1995; Petrides \& Furnham, 2000, 2001) describe a conception of emotional intelligence that includes many personality dispositions and traits such as motives, sociability and warmth. In this sense, EI is a blended ability and includes various components that are not restricted into the area in which cognition interacts with emotions. Ability models (i.e. Mayer \& Salovey, 1997), on the other hand, focus on mental abilities strictly related to the interaction between intelligence and emotions. In this context, EI is considered as a personality trait that is however different and independent from all other personality characteristics.
The scientific jury is still out there trying to decide whether ability or trait approaches are more appropriate to grasp the very essence of the notion. The debate may focus on theoretical or on empirical justification and reasoning. However, in order for one model to be considered as a legitimate contester in the arena of scientific legitimisation, one model should demonstrate strong links between the theoretical and the empirical level. Thus, since the final verdict is still pending, the reasons to prefer one theoretical construct over another is, at least partly, a function of the quality of the instruments and methods used to evaluate its assumptions.

This paper aims to contribute to the discussion about EI and provide additional evidence that would help the academic community decide whether emotional intelligence is a science or a myth (Matthews, Zeidner \& Roberts, 2004). Focusing on trait EI, and in particular the Bar-On's (1997) model of Emotional Social Intelligence, we will examine the validity and reliability of an instrument used for the assessment of EI. In specific, the main purpose of this paper is to examine the validity and reliability of the Greek version of the Emotional Quotient inventory (EQ-i). Examining the way EI is assessed, we hope to provide further empirical verification that would help clarify if EI, and in particular the Bar-On's (1997) model of Emotional and Social Intelligence, is not just a theoretical notion but also grounded science.

\subsection{The Bar-On's (1997) Emotional Quotient Inventory (EQ-i)}

The EQ- $i$ is the instrument used to assess EI as defined by Bar-On (1997, 2005, 2006). Emotional Intelligence according to Bar-On (ibid) is a crosssection of interrelated emotional and social competencies, skills and 
facilitators that determine how effectively we understand and express ourselves, how we understand others and relate with them, and how we cope with daily demands. Thus, the Bar-On model can be classified as a mixed or trait model of EI.

This particular instrument is a selfreport measure of emotionally and socially intelligent behaviour that provides an estimate of emotional-social intelligence. The EQ-i was the first measure of its kind to be published by a psychological test publisher (Bar-On, 1997), the first measure as such to be peer-reviewed in the Buros Mental Measurement Yearbook (Plake \& Impara, 1999) and the most widely used measure of emotional-social intelligence to date (Bar-On, 2005).

The instrument contains 133 items in the form of short sentences and employs a 5-point response scale with a textual response format ranging from "very seldom or not true of me" (1) to "very often true of me or true of me" (5). The individual's responses render a total EQ score and scores on the following 5 composite scales that comprise 15 subscale scores: Intrapersonal (comprising Self-Regard, Emotional Self-Awareness, Assertiveness, Independence, and SelfActualisation); Interpersonal (comprising Empathy, Social Responsibility, and Interpersonal Relationship); Stress Management (comprising Stress Tolerance and Impulse Control); Adaptability (comprising Reality-Testing, Flexibility, and Problem-Solving); and General Mood (comprising Optimism and Happiness).

Psychometric analyses of the EQ-i indicate that it has good internal reliability and test-retest reliability (Cronbach's alpha $=0.69-0.86$, retest reliability $=0.75-0.85)$. A considerable number of correlation studies reported in the manual support the validity of the EQ-i in terms of providing accurate measurement of the abilities needed to succeed in coping with environmental demands and pressures, and psychological well being. Furthermore, EQ-i scores correlate negatively with measures of poor emotional health such as depression and alexithymia (Bar-On, 1997; 2000; 2004).

However, there are still many unresolved issues concerning the discriminant validity of the instrument. EQ-i has not yet proved its discrepancy over other established instruments that measure personality traits, such as neuroticism and general affection (i.e. Bracket \& Mayer, 2003; Dawda \& Hart, 2000; Mayer, et al. 2000; Newsome, Day \& Catano, 2000). More evidence is required in order to prove that the EQ-i can actually further illuminate the unexplained variance in life satisfaction, job performance and psychological well-being.

To this extent, more evidence is required in order to justify the instruments' structural validity. Despite the fact that the EQ-i has been around for more than twenty years, few studies have examined its structural validity, and most of them were performed by Bar-On himself and several of his associates. Verifying the structural validity of the instrument is of course one of the many steps required to confirm that EI, is not "the same meat, new gravy" (Chapman, 2001), nor "a different way of slicing the same old cake" (Tossman, 1999). Notably, one of the major confines of emotional intelligence research is the lack of adequate evidence to support that EI constructs are different from older, more established psychological constructs (Joseph and Newman, 2010). Within this context, most of the criticism about trait EI has been focused on the fact that EI (and its subfacets) overlap with the well-known concepts of the Big Five 
personality traits (Davies, Stankov, \& Roberts, 1998; Eysenck, 1998; Landy, 2005).

Transcending the mere examination of EI as a solid entity and focusing on its constituting parts will provide insights of whether EI is indeed different from existing psychological constructs. We need to examine if EI is "a stripped Big Five" (de Raad, 2005) or a new cohesive structure, consisting of many other interrelated parts. It is therefore important to know how many subscales there are in a specific measurement tool and how they are related to each other. Thus, the aim of this article is not only to examine the reliability of the Greek version of the instrument but also to provide further insights concerning the EQ-i's construct validity. In this direction, further evidence will be produced to allow and not just judge the quality of the particular instrument but also help scientists understand the notion of EI better.

\section{Methods}

\subsection{Instrument}

The Greek version of the EQ-i was used under licence granted by Multi-Health Systems (MHS)- the company that holds the commercial rights of the instrument. For the purposes of the present study, we purchased a licence to reproduce/administer 300 inventories.

MHS requires a front and back translation for its psychometric instruments. Despite not being involved in the process of translating this particular instrument, we have been familiarised with the protocol used by MHS in the translation of another psychometric assessment of this company, the MSCEIT-V2 (see Neophytou, 2009; Neophytou, in press): Two people with proficient knowledge of Greek and English work independently to translate the instrument from English to Greek. After completing their individual translations, they discuss in order to reach a consensus and produce one single translation of the original document. Once the discussion is over, two other people, again with proficiency level in both languages work independently and then together to provide a translation of the questionnaire back into English. The back-into-English translation is compared to the original English version and all the necessary corrections are made on the Greek translation. The translated document (along with all its front and back translated versions) is sent to MHS and after a final check, the instrument is released.

\subsection{Participants}

This research was a follow up of an earlier, larger research project (Kyriakides \& Creemers, 2006) that examined teachers and teaching in order to establish the factors that determine effectiveness of instruction. As the results of the Kyriakides \& Creemers (2006) study suggested, more than $25 \%$ of the variance in effectiveness remained unexplained. Hence, the overall aim of the current research design was to provide additional insights about the previous project, examining whether EI could explain the unaccounted variance in terms of instructional effectiveness. Validating the research instruments was one of the objectives of the overall research design. Consequently, the target sample consisted of the teachers that took part in the previous study. As Kyriakides \& Creemers (2006) report, these teachers were chosen through stratified sampling (Cohen, Manion, \& Morrison, 2000) $(n=208)$. However, only 82 of them agreed to participate in the current venture. Hence, the sample was expanded including 128 undergraduate 
students of the pedagogical department at the University of Cyprus, in order to reach the target of 300- the number of participants that our license to administer/reproduce allowed. The Greek "pen and paper" version of the EQ-i was administered to the participants following the guidelines provided in the instrument's technical manual (Bar-On, 1997): the purpose of the research was explained, the participants provided informed consent, and the researchers administered and collected the tests in quiet settings- allowing a response time of (about) 40 minutes.

After all tests were returned, an initial evaluation was performed to examine the number of omitted items and the degree of inconsistency in responding to similar types of items. Further, we examined if the respondents were attempting to give an overly positive or negative impression. Thus, following the steps proposed in the technical manual (Bar-On, 1997), three indexes were examined: the Inconsistency Index, the Omission Rate and the scales of Positive and Negative Impression: The Inconsistency Index is calculated by summing the differences in scores of ten pairs of similar items and should be less than 12. The Omission Rate indicates the number of incomplete items and should be less than 6\%. Finally the Positive and Negative Impression scales consist of certain items that detect respondents who may be giving an exaggerated positive or negative impression of themselves. When the results in either of these scales exceed two standard deviations from the mean (30 points), the results are considered invalid. Thus, after examining all the aforementioned criteria, the final sample was narrowed down to 272 respondents aged $18-53$ ( $23 \%$ male $87 \%$ female).

\subsection{Reliability}

The internal reliability of the instrument was examined using the Cronbach's alpha coefficient. This was found to be very high concerning the total scale (0.94) and more than adequate for all the subscales ranging from 0.77 to 0.91 . In particular the values for each of the composite scale were the following: Intrapersonal (0.91) Interpersonal (0.86) Stress Management (0.75) Adaptability (0.83) and General Mood (0.77).

Even though an alpha that high may seem to provide sufficient evidence of the instrument's internal reliability, as Raykov $(1997,1998)$ argues, it may overor under- estimate reliability. Reliability, as assessed by Cronbach's alpha, is based on indicators intercorrelations: the higher they are, the higher alpha is. However, high alpha doesn't guarantee unidimensionality. The more unmodelled residual covariance, the more Cronbach's alpha will be an overestimate of reliability Raykov (2001). Hence, attempting to overcome this possible problem, after the examination of the internal reliability of the instrument, analysis was focused on its factorial validity. This was done by a combination of exploratory and confirmatory factor analysis (CFA).

A similar process has also been employed by Bar-On (1997) who applied a number of exploratory factor analyses to examine the theoretical breakdown of the subscales and thereby the construct validity of the inventory. As he reports, the results were used to change certain items, which seemed to more appropriately belong to subscales other than those originally assigned. CFA was afterwards used to determine whether it is possible to treat the composite subscales as separate factors. Examining different factorial models, he concluded that the notion of EI consists of five composite factors which in turn, can be partitioned into 15 subcomponents (GFI=.971, Adjusted $\mathrm{GFI}=.892, \mathrm{NNFI}=.956, \mathrm{CFI}=.982)$. 
Exploratory factor analysis is therefore performed when we try to establish the appropriate number of factors in order to explain the relation between the observed variables. On the other hand confirmatory factor analysis is used when there is a pre-existing model structure guiding the research (Kline, 1994). Thus, following Bar-On's example in our research, exploratory factor analysis examined how our empirical data were grouped into factors while confirmatory factor analysis clarified whether the factor structure that emerged from our data could match the models' existing conceptual structure.

\subsection{Exploratory factor analysis- discovering first order factors}

Separate principal component factor analyses were employed for all the subscales of the instrument. Despite the limitations that the method of Principal Component Analysis may have in terms of differentiation between common and unique variance, PCA was employed following Bar-On's (1998) proposed methodology. PCA is the simplest of the true eigenvector-based multivariate analyses. Through its simplicity, it can be thought of as illuminating of the internal structure of the data in a way that best explains the variance in the data (Jolliffe, 1986).

At this stage of the analysis, we examined whether the discrete items of the questionnaire could form first order factors and whether the factors that emerged from our data reflected the proposed structure of the instrument. For example, concerning the subscale Self Regard the technical manual suggests that this consists of the questions $11,24,40,56,70,85,100$, 114, 129. Therefore, these items were factor analysed in order to examine their underlying empirical structure. Again, consistence with the approach suggested by Bar-On (1997) item analysis was applied to the data before factor analysis. Employing item analysis in selecting items to be factor analysed later, makes good statistical sense since item analysis increases the proportion of true variance in the remaining subscale items, which tends to increase their commonality and hence, their loadings on common factors (Guilford \& Fruchter, 1978 cited in Bar-On, 1997, p.102).

Exploratory factor analysis with obliquevarimax rotation was performed using the SPSS 15 statistical software. According to Fabrigar et al. (1999) oblique rotations will produce a better estimate of the true factors and a better simple structure than will an orthogonal rotation.

To determine the appropriate number of factors for the factor analysis solution, a criteria of eignevalues greater than one (Kaiser, 1960) was used as a guide, and then a scree plot (Cattel, 1966) was examined, comparing different solutions in terms of interpretability. Since, the Kaiser criterion may sometimes retain too many factors while the scree test sometimes retains too few (Hill \& Lewicki, 2006), both criteria were used in order to provide the best possible solution. Applying additional criteria (i.e. the first factor to account for more than half of the variance, factor loading $>0.40$, loadings to more than one factor with second factor loading $>0.3$ and difference between the two factors loadings $>0.10$, Cronbach's Alpha and Pearson Correlation $>0.3$ ) items were entered or removed in order to obtain the most interpretable and parsimonious solution.

Negative loadings were also scrutinised. However, analysis did not reveal any strong negative loadings. All the observed negative loadings were very low (ranging from -0.03 to -0.150 ) while their difference from the loading on the first factor was very high (the 
difference in the absolute value between negative loadings and first factor loading was in all cases more than 0.6

Analysis revealed a somehow different factorial structure concerning the subscales than the structure suggested in the instrument's technical manual ${ }^{1}$. In specific, the structure that emerged from our data included 35 instead of 15 first order factors. All of the proposed factors were broken down into two or more factors. Only the subscales of Self Regard and Independence retained their single factor structure. The internal reliability of the new subscales was examined using Cronbach's alpha coefficient. In cases where factors consisted from only two items, Pearson Correlation index was examined. Four items $(2,78,87,89)$ were excluded since they could not load to any of the factors. Table 1 presents the original

EQ-i Scales (as suggested by the technical manual) and the new factorial structure derived from the exploratory factor analysis of the Greek EQ-i.

According to table 1 the subscales consisting the composite scale of Intrapersonal Relations were broken down into 9 other subscales. Excluding the Self Regard subscale which remained intact, all other subscales were divided into two factors. Thus, Self-Awareness was broken down into the following subscales: (a) Expressing Emotions (33\% of the variance, $a=0.73$ ) and, (b) Understanding Emotions $(20 \%$ of the variance, $a=0.61)$. In a similar manner, Assertiveness was found to include these subscales: (a) Disagreeing-Expressing Anger (33\% of the

\footnotetext{
1 One may argue that the different factorial structure is the outcome of sociocultural differences. However, since no empirical justification exists at the moment, any conclusion will be arbitrary. Further research is therefore required in this direction.
}

variance, $\mathrm{a}=0.58$ ) and (b) Assertiveness, Claiming One's Rights $(27 \%$ of the variance, $r=0.55 \mathrm{df}=270, \mathrm{p}<0.001)$. Next, the Independence subscale was formed by the subscales (a) Being a Leader (39\% of the variance, $a=0.67$ ) and, (b) Being Attached to Something (17\% of the variance, $\mathrm{r}=0.28, \mathrm{df}=272, \mathrm{p}<0.001)$. In a similar manner Self-Actualisation consisted of the subscales of (a) Knowing your Abilities and Purpose in Life (38\% of the variance, $a=0.68$ ) and (b) Being Able to Find Happiness $(17 \%$ of the variance, $\mathrm{a}=0.64$ ).

Factor analysis, of the suggested by the technical manual items composing the Interpersonal scale, resulted into 10 instead of 3 subscales. As presented into table 1, the Empathy scale was broken down into (a) Caring for Others (33\% of the variance, $a=0.6$ ) and (b) Understanding Others $(17 \%, \quad \mathrm{a}=0.63)$. The Social Responsibility scale was broken into the subscales of (a) Helping and Supporting Others (30\%, a=0,52), (b) Being Sensitive to the Pain and the Emotions of Others $(18 \%$ of the variance, $r=0,42$, $\mathrm{df}=270, \mathrm{p}<0.001$ ), (c) Respecting the Law (15\% of the variance, $\mathrm{r}=0.54, \mathrm{df}=270$, $\mathrm{p}<0.001)$. Concerning the Social Responsibility scale, items that could not be included into any of the factors above were separately factor analysed. A new factor emerged, named Respecting and not Exploiting Others accounting for $49 \%$ of the variance $(a=0.44)$. Finally, varimax rotation of the proposed items for subscale of Interpersonal relations produced four factors: (a) Being an Agreeable Companion (30\%, a $=0.47)$, (b) Creating Friendly Relations $(11 \%$, a =0.47), (c) Allocating high importance to Friendship (11\% of the variance, $\mathrm{r}=0.23, \mathrm{df}=270, \mathrm{p}<0.001), \quad(\mathrm{d})$ Ability to Share Deep emotions and Show Affection (10\% of the variance, $\mathrm{r}=0.28$, $\mathrm{df}=270, \mathrm{p}<0.001)$. 
Table 1.Original EQ-i Scales (as suggested by the technical manual) and the empirical scales derived from the exploratory factor analysis of the Greek EQ-i.

\begin{tabular}{|c|c|c|c|}
\hline \multicolumn{3}{|c|}{$\begin{array}{l}\text { Scales suggested by the Technical manual of the } \\
\text { instrument }\end{array}$} & \multirow[t]{2}{*}{ Empirical subscales (factors from our data) } \\
\hline $\begin{array}{l}\text { Total } \\
\text { EQ-i scale }\end{array}$ & $\begin{array}{l}\text { Composite } \\
\text { Scales }\end{array}$ & Subscales & \\
\hline \multirow{15}{*}{$\begin{array}{l}\text { Emotional } \\
\text { Social } \\
\text { Intelligence }\end{array}$} & \multirow{5}{*}{ Intrapersonal } & Self-Regard & 1. Self-Regard (same) \\
\hline & & Self-Awareness & $\begin{array}{ll}\text { 2. } & \text { Expressing Emotions } \\
\text { 3. } & \text { Understanding emotions } \\
\end{array}$ \\
\hline & & Assertiveness & $\begin{array}{ll}\text { 4. } & \text { Disagreeing-Expressing Anger } \\
\text { 5. } & \text { Assertiveness, claiming ones rights } \\
\end{array}$ \\
\hline & & Independence & $\begin{array}{ll}\text { 6. } & \text { Being a leader } \\
\text { 7. } & \text { Being attached to something } \\
\end{array}$ \\
\hline & & Self-Actualization & $\begin{array}{l}\text { 8. Knowing your abilities and purpose in life } \\
\text { 9. }\end{array}$ \\
\hline & \multirow[b]{3}{*}{ Interpersonal } & Empathy & $\begin{array}{l}\text { 10. Caring for others } \\
\text { 11. Understanding others }\end{array}$ \\
\hline & & $\begin{array}{l}\text { Social } \\
\text { Responsibility }\end{array}$ & $\begin{array}{l}\text { 12. Helping and supporting others } \\
\text { 13. Being sensitive to the pain and the emotions of } \\
\text { other } \\
\text { 14. Respecting the law } \\
\text { 15. Respecting and not exploiting others. }\end{array}$ \\
\hline & & $\begin{array}{l}\text { Interpersonal } \\
\text { Relationship }\end{array}$ & $\begin{array}{l}\text { 16. Being an agreeable companion } \\
\text { 17. Creating friendly relations } \\
\text { 18. Allocating high importance to friendship } \\
\text { 19. Ability to share deep emotions and show affection. }\end{array}$ \\
\hline & \multirow[b]{3}{*}{ Adaptability } & Reality-Testing & $\begin{array}{l}\text { 20. Controlling imagination, daydreaming and } \\
\text { exaggeration } \\
\text { 21. Keeping in touch with people and the environment. } \\
\text { 22. Effectiveness in perceiving emotions and reality. } \\
\text { 23. Difficulty to perceive emotions and reality. }\end{array}$ \\
\hline & & Flexibility & $\begin{array}{ll}\text { 24. } & \text { Ability to adjust } \\
\text { 25. } & \text { Ability to change } \\
\end{array}$ \\
\hline & & Problem Solving & $\begin{array}{l}\text { 26. Ability for analytical reasoning } \\
\text { 27. Difficulty in problem solving }\end{array}$ \\
\hline & \multirow{2}{*}{$\begin{array}{l}\text { Stress } \\
\text { Management }\end{array}$} & Stress Tolerance & $\begin{array}{l}\text { 28. Managing stress } \\
\text { 29. Being effective under stressful situations }\end{array}$ \\
\hline & & Impulse Control & $\begin{array}{l}\text { 30. } \text { Controlling anger } \\
\text { 31. Suppressing impulses }\end{array}$ \\
\hline & \multirow[b]{2}{*}{ General Mood } & Optimism & 32. Optimism \\
\hline & & Happiness & $\begin{array}{l}\text { 33. } \\
\text { 34. } \\
\text { 3eing a joyful person able to enjoy life } \\
\text { 3eing able to dwell happiness and pleasure. }\end{array}$ \\
\hline
\end{tabular}

Adaptability was broken down into 8 factors. Thus, Reality-Testing appeared to be the outcome of (a) Controlling Imagination, Daydreaming and Exaggeration (26\%, a $=0.57)$, (b) Keeping in Touch with People and the Environment (17\%, a=0.49) and (c) Effectiveness in Perceiving Emotions and Reality (13\% of the variance, $\mathrm{r}=0.20, \mathrm{df}=270, \mathrm{p}<0.001$ ). Items not included in this factorial 
structure formed another factor, Difficulty to Perceive Emotions and Reality, responsible for $62 \%$ of the variance $(\mathrm{r}=0.23, \mathrm{df}=270, \mathrm{p}<0.001)$. The subscale of Flexibility consisted of the factor (a) Ability to Adjust (39\%, $\mathrm{a}=0.78)$ and (b)Ability to Change (18\%, a=0,48). Finally Ability for Analytical Reasoning (39\%, a $=0.72)$ and Difficulty in Problem Solving $(r=0.40, \quad \mathrm{df}=270, \quad \mathrm{p}<0.001)$ constituted the Problem Solving subscale.

The rotation of the items comprising the Stress management scale resulted into four factors. The Stress tolerance subscale was found to include two factors, (a) Managing Stress (40\%, $a=0,78)$ and (b) Being Effective under Stressful Situations (15\%, a=0.62). Two factors were found to form the Impulse control subscale of the Stress Management scale: (a) Controlling Anger (42\%, $\mathrm{a}=0.81$ ) and (b) Suppressing Impulses (19\%, $\mathrm{a}=0.65$ ).

The subscales of Optimism and Happiness, which are composing the EQ-i's scale of General Mood, were broken down into four factors. Optimism remained a single factor (45\%, a=0.79) while three factors created the structure of Happiness: (a) Being a Joyful Person (34\%, a=0,7), (b) Being able to Enjoy Life (16\%, a=0.65) and (c) Being able to Dwell Happiness and Pleasure $(r=0.30 \mathrm{df}=270, \mathrm{p}<0.001)$.

\subsection{Confirmatory factor analysis}

The conceptual models were tested through the structural equation modelling (SEM) using EQS (Bentler, 1995). All first order factors that emerged from our data were treated as independent variables. Using the technical manual's proposed second order factorial structure we examined whether our empirical factors (constituting the variables of the analysis) could justify the suggested structure in terms of first order factors (representing EQ-i's subscales) and second order factors (representing the composite scales).

In this study the $\chi^{2} / \mathrm{df}, \mathrm{CFI}$ (Bentler, 1990) and RMSEA (Brown \& Mels, 1990) were adopted and each model was estimated, using the Maximum Likelihood Theory (ML). The Root Mean Square Error of Approximation (RMSEA) is a parsimony-adjusted index in which values less than about 0.05 indicate close approximate fit and RMSEA greater or equal to 0.10 suggests poor fit. CFI index should range from 0 to 1 and values greater than 0.90 are indicative of a well-fitting model. The index $\chi^{2} / \mathrm{df}$ was adopted in order to overcome the common problem associated with the sensitivity to the size of the correlation and the sample size of the likelihood ratio chi-square test. Hence the likelihood ratio chisquare divided by the degrees of freedom should be less than 2 for a good fitting model (Kline, 2005). Figures 1-5 present the first and second factor loadings for each one of the EQi's composite scales.

Figure 1 presents the first and second order factor loadings for the Intrapersonal scale. All indexes used to test the factorial structure of the Intrapersonal scale had satisfactory values $\quad\left(\chi^{2}=46.31, \quad \mathrm{df}=23, \quad \mathrm{p}<0.05\right.$, RMSEA $=0.002, \quad$ CFI $=0.963) . \quad$ The standardised factor loadings were all positive and moderately high. Their standardised values ranged from 0.63 to 0.74 and five of them were 0.70 and higher. All the first order factors (representing the subscales of the EQ-i) loaded onto the second order factor (representing the intrapersonal Scale) and most of their values were near 0.60. 
Figure 1: First and second order factor model for the EQ-i concerning the composite scale of Intrapersonal Relations and its empirical subscales

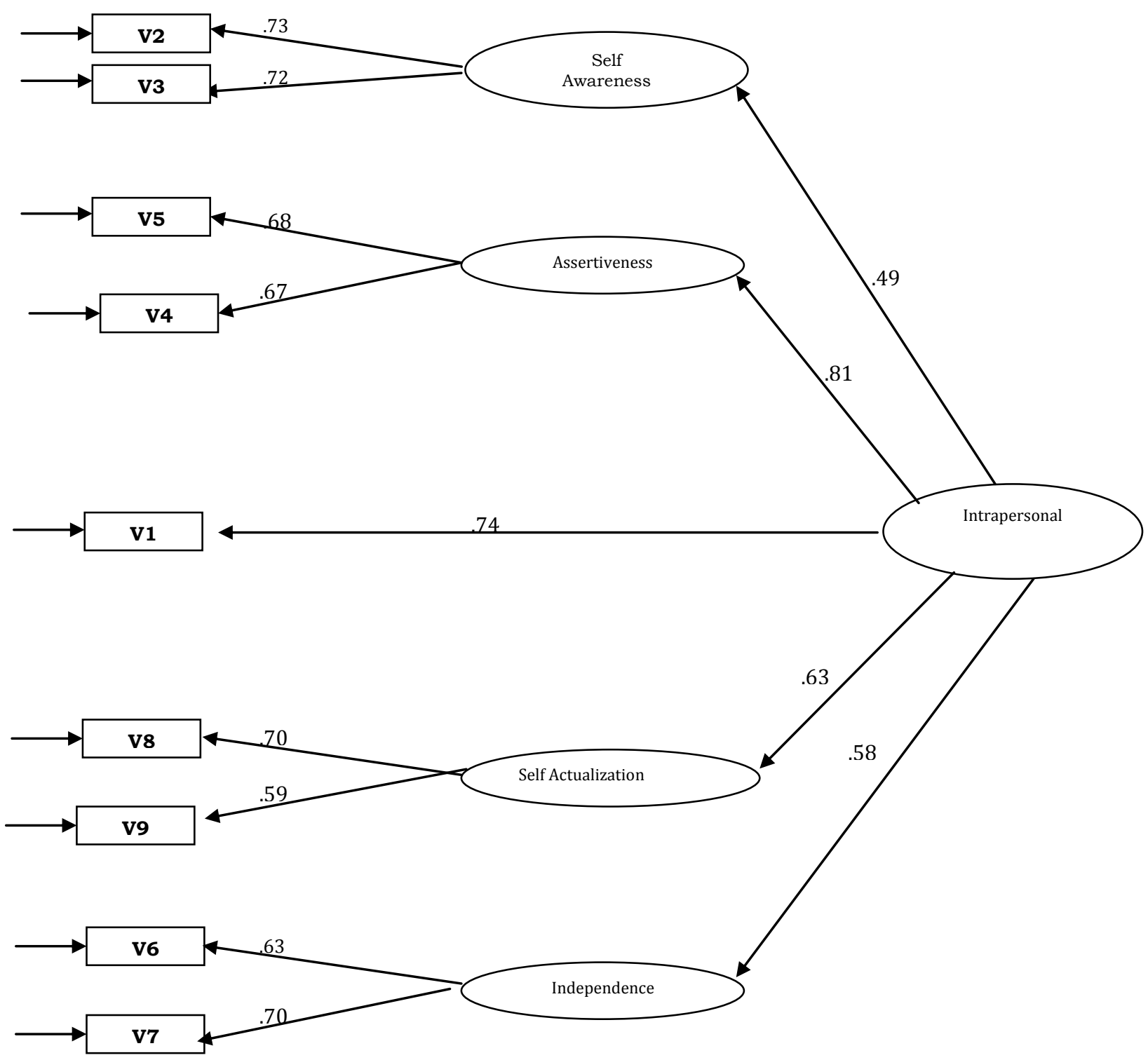

$\mathrm{v} 1=$ Self-Regard, v2= Expressing Emotions v3= Understanding emotions, v4= Disagreeing-Expressing Anger, v5 = Assertiveness, claiming ones rights, v6= Being a leader, v7 = Being attached to something $\mathrm{v} 8=$ Knowing your abilities and purpose in life Being a leader, v9=v7= Being able to find happiness,

The results of the first and second order CFA concerning the Interpersonal scale appear in Figure 2. All the first order factors included in this model have positive loadings to the second order factor (Interpersonal factors). All the standardised loadings (for both first and second order factors) range from 0.58 to 0.70, with the exception of the Empathy subscale, which appears to have a lower value (0.48). Goodness of fit indicators produced satisfactory results $\left(\chi^{2}=5.17\right.$, $\mathrm{df}=3, \mathrm{p}<0.29, \mathrm{RMSEA}=0.002, \mathrm{CFI}=0.973)$. Despite the fact that 10 factors resulted 
from the exploratory factor analysis, CFA could only include 5 of them. Therefore, the final model was found to include the two first order factors comprising Empathy, two out of four factors comprising Interpersonal
Relations and one of the four factors comprising Social Responsibility. This last factor was not however loaded to a first order factor. It was directly related to the second order factor (0.70).

Figure 2: First and second order factor model for the EQ-i concerning the composite scale of Interpersonal Relations and its empirical subscales.

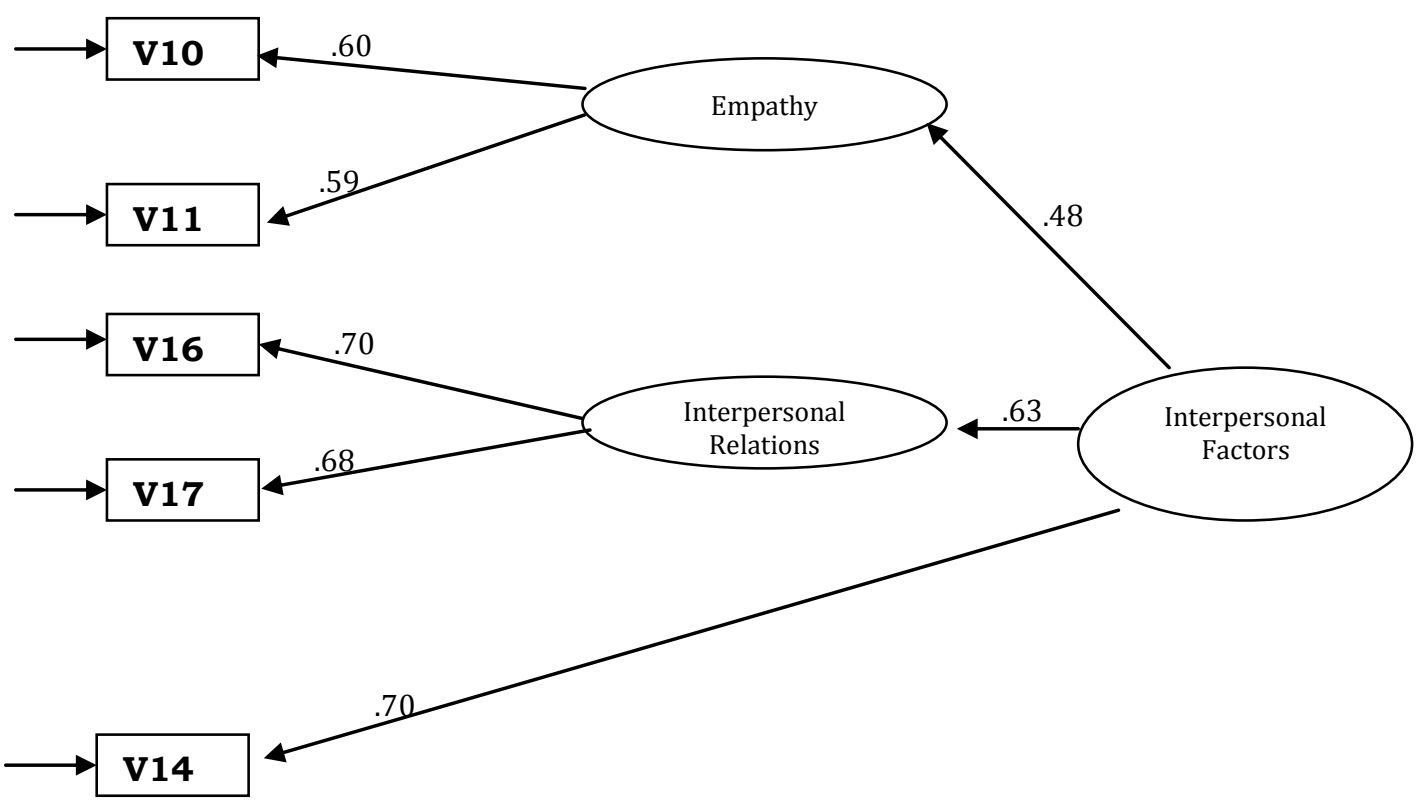

$\mathrm{v} 10=$ Caring for others, v11=Understanding others, v14=Respecting the law, v16= Being an agreeable companion, v17= Creating friendly relations,.

Regarding the Adaptability scale (Figure 3), goodness of fit indicators were also found to be satisfactory $\left(\chi^{2}=14.7, \mathrm{df}=11, \mathrm{p}<0.21\right.$, RMSEA $=0.004$, $\mathrm{CFI}=0.963)$. CFA revealed that all the empirical first order factors could be included in the final model with the exception of Factor 22 (Effectiveness in perceiving emotions and reality). The standardized factor loadings were all positive and ranged from 0.59 to 0.72 .
The model that emerged concerning the Stress management scale also proved to be a good fit for our data (Just identified, $\mathrm{df}=0$ ). As presented in Figure 4, all factor loadings have positive and moderately high values. All first order factors loaded on to the second order factor having values over 0.60 while the loadings of the two first order factors on the second order factor was 0.71 and 0.80 . 
Figure 3: First and second order factor model for the EQ-i concerning the composite scale of Adaptability factors and its empirical subscales

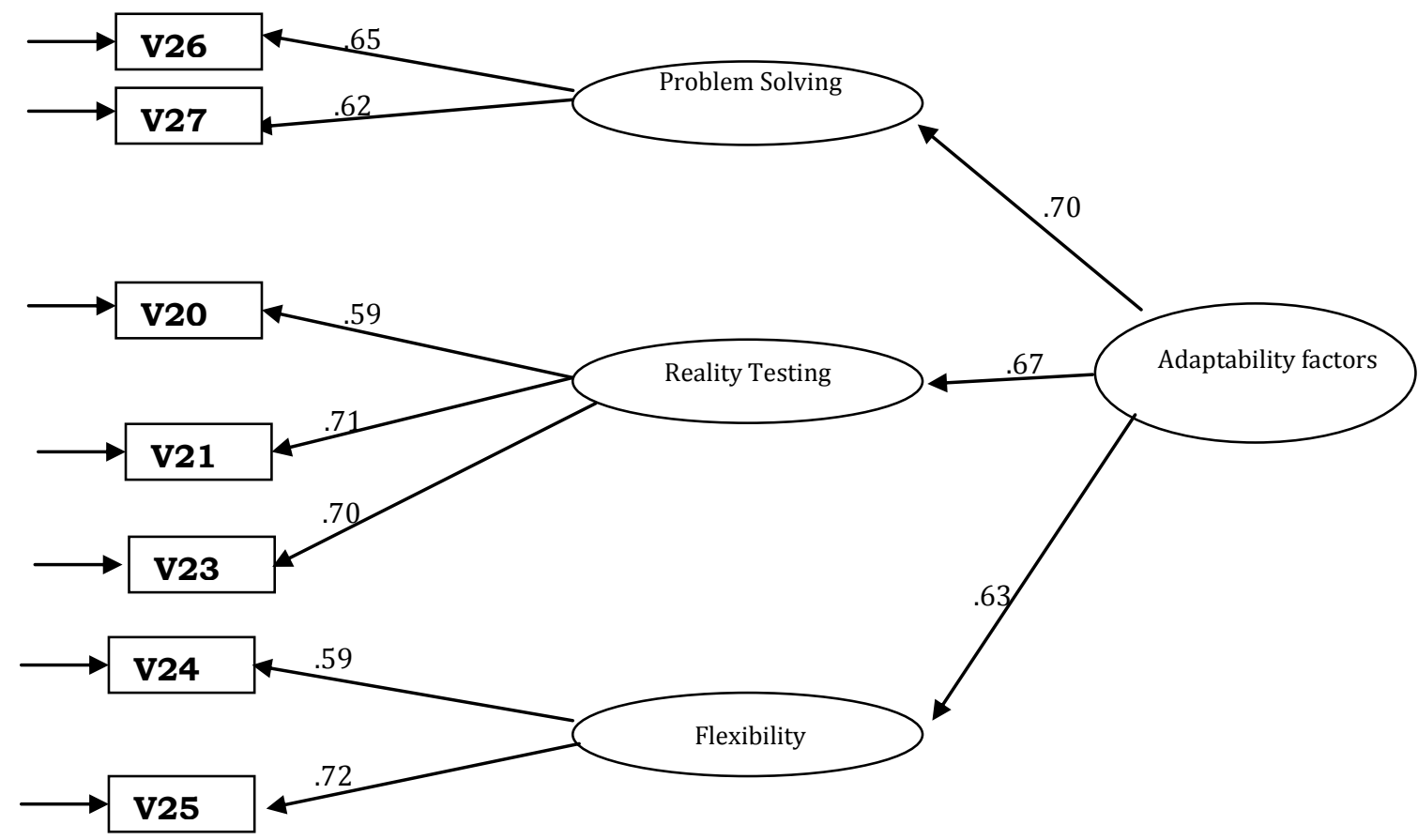

v26= Ability for analytical reasoning, v27= Difficulty in problem solving, v20 = Controlling imagination, daydreaming and exaggeration, v21= Keeping in touch with people and the environment, v23= Difficulty to perceive emotions and reality, v24=Ability to adjust, v25= Ability to change

Figure 4: First and second order factor model for the EQ-i concerning the composite scale of Stress management and its empirical subscales

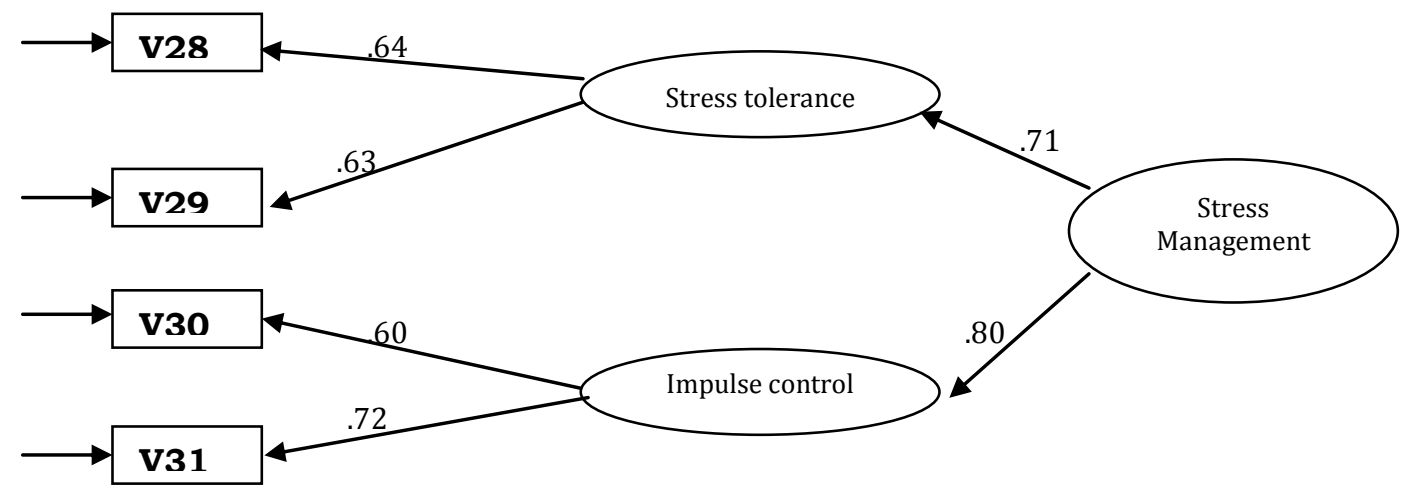

v28 $=$ Managing stress, v29 $=$ Being effective under stressful situations, v30 $=$ Controlling anger, v31= Suppressing impulses 
Finally, CFE concerning the scale of General mood resulted in a structure that bypasses all first order factors. As shown on Figure 5, all the variables (factors from the Exploratory factor analysis) load directly on to the second order factor representing the General mood scale. This structure had a satisfactory fit $\left(\chi^{2}=3.84 \mathrm{df}=2, \quad \mathrm{p}<0.06\right.$, RMSEA $=0.002, \quad \mathrm{CFI}=0.968)$ and good loadings ranging from 0.64 to 0.72 .

Figure 5: First and second order factor model for the EQ-i concerning the composite scale of General mood and its empirical subscales

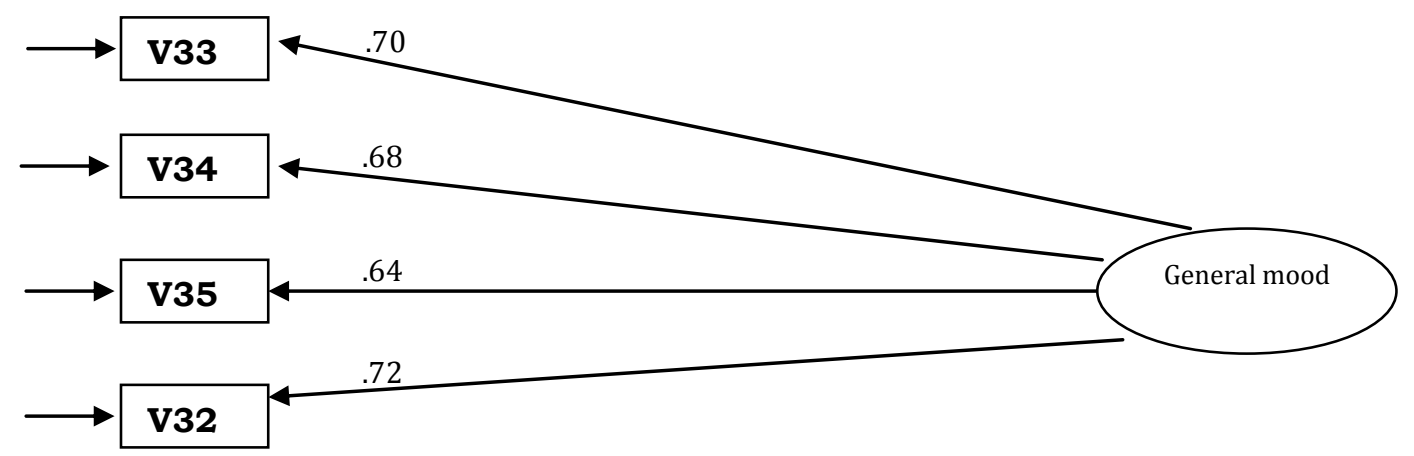

V33=Being a joyful person, v34=Being able to enjoy life, v35=Being able to dwell happiness and pleasure form life, v32=Optimism

Table 2 summarises the fit criteria for each of the EQ-i' s composite scales. Despite the slight modifications observed in the factorial structure of the composite scales (second order factors), our data support the model's structure. As shown in table 2, all goodness of fit indexes are gratified for all the EQ-i composite scales.
Thus, we may conclude that the theoretical structure underlying the emotional and social abilities of Intrapersonal Skills, Interpersonal Relations, Stress Management abilities, Adaptability and General Mood of the Bar-On's (1997) model have an empirical validation in the case of the instrument's Greek version.

Table 2. Fit criteria for the total and composite scales of EQ-i

\begin{tabular}{llccc}
\hline Scale & $\mathrm{X}^{2} / \mathrm{df}<2$ & CFI $>90$ & RMSEA $<.05$ & $\mathrm{p}$ \\
\hline Intrapersonal & $2.0(46.3 / 23)$ & .96 & .002 & .05 \\
Interpersonal & $1.7(5.1 / 3)$ & .97 & .002 & .29 \\
Adaptability & $1.3(14.7 / 11)$ & .96 & .004 & .21 \\
Stress Management & & $\mathrm{Df}=0$ & (Just identified) & \\
General Mood & $1.9(3.84 / 2)$ & .96 & .002 & .06 \\
Total Scale & $11(58.5 / 5)$ & .91 & .16 & .001 \\
\hline
\end{tabular}


Goodness of fit indicators were also examined in order to check whether our data could support the overarching structure of the EQ-i: particularly, if the five second order factors (representing the instrument's composite scales) could be included into one third order factor representing an individual's general-total score of Emotional Social Intelligence. Concerning however the structure of General ESI factor, goodness of fit analysis produced unsatisfactory results $\left(\chi^{2}=58.5, \quad \mathrm{df}=5, \quad \chi^{2} / \mathrm{df}=11, \quad \mathrm{p}=0.001\right.$, RMSEA $=0.16, \mathrm{CFI}=0.91)$.

\section{Discussion}

Results from the current study indicate that the internal reliability of the Greek version of the instrument is very high. Our research provides additional support to the results reported by BarOn (1997). As Bar-On's research indicates, the scales of the instrument, being tested across seven population samples, have produced average-to-high internal consistency coefficients (Cronbach alpha ranging from 0.69 to 0.86). EQ-i therefore appears to be a reliable instrument to be used across different population samples justifying its numerous translations and its characterisation as one of the most advanced self-report measures of Emotional Intelligence currently available.

Despite the apparent reliability that the instrument demonstrates, our results suggest caution in terms of its structural validity. According to the theoretical model of Emotional Social Intelligence (ESI) there should be a 1-5-15 (total ESI-ESI abilities/key components- ESI skills) (Bar-On, 2005). This structure is reflected in the EQ-i, which consists of one total scale, 5 composite scales and 15 subscales. Thus, construct validity should provide empirical justification of the 1-515 structures. Results of the current study however failed to support the 1-5-
15 theoretical model and any of the alternatives provided by Bar-On (1997, 2000 , 2004). Exploratory factor analysis of our data set, revealed 35 instead of 15 factors representing the instruments subscales while confirmatory factor analysis indicated that only 29 of these factors could be loaded onto the second order factors (reflecting the five composite scales of the instrument). Further, none of the 5 second-order factors could be loaded onto one thirdorder factor representing the total EQ-i scale.

The few other studies examining the EQi's in terms of the 1-5-15 structure (i.e. Bar-On, 1997; Dawda \& Hart, 2000; Palmer et al., 2003) have also failed to support in total the instrument's underlying theoretical model. Thus, several proxies of this structure are reported. In terms of exploratory factor analysis, even Bar-On (1997) himself examined several alternative factor solutions $(12,13,14)$ and concluded that a 13-factor varimax rotated solution afforded the most meaningful theoretical interpretation (p.103). Further analysing these results through confirmatory factor analysis Bar-On (2000) suggested a 10factor structure as an alternative to the 15-factor structure. Different results are reported by Dawda \& Hart (2000), who questioned the usefulness of the five intermediate level composite scales and suggested to use the 15 subscale scores directly. Palmer et al (2003) provide another model consisting of a general factor of emotional intelligence and six other primary factors.

Apparently, empirical evidence providing an exact match for the 1-5-15 dimensional structure of the EQ-i has not yet been found. However, what the existing studies reveal (Bar-On, 1997; Dawda \& Hart, 2000; Palmer et al., 2003) is that despite the fact that the structure of the composite scales/subscales is not an 
exact match to the theoretical model, still the structure reflecting a general factor of emotional intelligence is, more or less, confirmed. Our results appear to be somehow different than those reported by other studies revealing a 5-29 factorial structure. However, despite the fact that these 5 scales are the outcome of 29 instead of 15 factors, the theoretical structure concerning the second order factors remains the same. This structure cannot however be projected onto a higher order factor representing a total EI scale. Thus, our results cannot support the existence of a third order general factor reflecting general Emotional Intelligence.

\section{Conclusion}

Theory is validated by research. Different findings are the outcome of different research designs and methods of analysis. The diverse results reported in the few studies to examine the factorial structure of the EQ-i are, in part, a result of the different methods used for analysing data. Banning a theoretical model can only be done when researchers, beyond any reasonable doubt, convince that their methods are flawless. Safe conclusions need safe methods. Still, a final verdict about the optimum method is probably a utopia. Therefore, until the establishment of the final perfect method for evaluating a theory, scholars can contribute to the existing discourse by presenting their arguments and methods bearing however in mind that their methods will also be subjected to criticism and evaluation. In this sense, good research designs may be replicated across diverse and different populations and provide further insights about the theory upon which models are based.

The present study is also subjected to various limitations such as the limited sample size and the lack of evidence about the specific socio-lingual context. A more thorough investigation is necessary in order to show how the translated version of the inventory's total and composite scales correlate with various scale scores of other measures that evaluate relative constructs. Thus, further research is required to validate the instrument, especially in light of the accumulated criticism concerning the scientific validity and innovation of the notion. The validation of the instruments used to provide empirical justification to a controversial notion is thereby crucial.

EI needs to convince the scientific jury that it is neither a "new way of slicing the same old cake" nor "old wine in new bottles", but something inversely unique. It is therefore essential to prove that EI is not rebranding, not new arrangement of existing ingredients but a robust and cohesive entity. To this extent, we need to examine the notion both holistically and in terms of its different constituting parts.

\section{References}

Bar-On, R. (1997). The Emotional Quotient Inventory (EQ-i): Technical manual. Toronto, Canada: Multi-Health Systems, Inc. [Abstract] [Back to text]

Bar-On, R. (2000). Emotional and social intelligence: Insights from the Emotional Quotient Inventory (EQ-i). In R. Bar-On and J. D. A. Parker (Eds.), Handbook of emotional intelligence. San Francisco: Jossey-Bass (pp. 363388). [Abstract] [Back to text] 
Bar-On, R. (2004). The Bar-On Emotional Quotient Inventory (EQ-i): Rationale, description, and summary of psychometric properties. In Glenn Geher (Ed.), Measuring emotional intelligence: Common ground and controversy. Hauppauge, NY: Nova Science Publishers (pp. 111-42). [Full text] [Back to text]

Bar-On, R. (2005). The Bar-On model of emotional-social intelligence. In P. Fernández-Berrocal and $\mathrm{N}$. Extremera (Guest Editors), Special Issue on Emotional Intelligence. Psicothema, 17. [Full text] [Back to text]

Bar-On, R. (2006). The Bar-On Model of Emotional-Social Intelligence (ESI). Psicothema, 18, supl., 1325. [Full text] [Back to text]

Bentler, P. M. (1995). EQS: Structural equations program manual. Encino California: Multivariate Software Inc. [Full text] [Back to text]

Bracket, M.A., \& Mayer, J.D. (2003). Convergent, discriminant and incremental validity of competing model of measures of emotional intelligence. Personality and Social Psychology Bulletin, 29(9), 1-12. [Abstract] [Back to text]

Brown, M. W., \& Mels, G. (1990). Ramona PC: User Manual. Pretoria: University of South Africa. [Back to text]

Cattell, R. B. (1966). The scree test for the number of factors. Multivariate Behavioral Research, 1, 629-637. [Full text] [Back to text]
Chapman, M. (2001). The EI debate: Emotionally challenged. People Management 7(8), 40. [Back to text]

Davies, M., Stankov, L., \& Roberts, R. D. (1998). Emotional intelligence: In search of an elusive construct. Journal of Personality and Social Psychology, 75, 989-1015. [Abstract] [Back to text]

Dawda, D., \& Hart,S. D. (2000). Assessing emotional intelligence: reliability and validity of the BarOn Emotional Quotient Inventory (1997; 2000) in university students. Personality and Individual Differences, 28, 797812. [Full text] [Back to text]

de Raad, B. (2005). The trait-coverage of emotional intelligence. Personality and Individual Differences, 38, 673-687. [Full text] [Back to text]

Eysenck, H. J. (1998). Intelligence: A new look. New Brunswick, NJ: Transaction. [Full text] [Back to text]

Fabrigar, L. R., Wegener, D. T., MacCallum, R. C., \& Strahan, E. J. (1999). Evaluating the use of exploratory factor analysis in psychological research. Psychological Methods, 4(3), 272299. [Abstract] [Back to text]

Gardner, H. (1983). Frames of mind. New York: Basic Books. [Abstract] [Back to text]

Goleman, D. (1995). Emotional intelligence. New York: Bantam Books. [Abstract] [Back to text]

Jolliffe, I. T. (1986). Principal Component Analysis. Springer-Verlag. [Full text] [Back to text] 
Joseph, D.L \& Newman, D.A. (2010). Discriminant validity of selfreported emotional intelligence: a multitrait-multisource study. Educational and Psychological Measurement, 70(4). 672-694. [Full text] [Back to text]

Kaiser, H. F. (1960). The application of electronic computers to factor analysis. Educational and Psychological Measurement, 20, 141-151. [Full text] [Back to text]

Kline,P. (1994). An easy guide to factor analysis. London: Routledge. [Full text] [Back to text]

Kline,P. (2000). Handbook of psychological testing (2nd ed.). London: Routledge. [Full text] [Back to text]

Kyriakides, L. \& Creemers, B.P.M. (2006). Testing the dynamic model of educational effectiveness: Teacher effects on cognitive and affective outcomes. Paper presented at the $87^{\text {th }}$ Annual Meeting of the American Educational Research Association. Chicago, USA. [Full text] [Back to text]

Landy, F. J. (2005). Some historical and scientific issues related to research on emotional intelligence. Journal of Organizational Behavior, 26, 411-424. [Full text] [Back to text]

Matthews,G., Zeidner,M. \&. Roberts, R.D. (2004). Emotional intelligence: science and myth. USA: MIT Press. [Full text] [Back to text]

Mayer, J. D., \& Ciarrochi, J. (2006). Clarifying concepts related to emotional intelligence: A proposed glossary. In J. Ciarrochi, J. Forgas, \& J. D. Mayer (Eds). Emotional intelligence in everyday life (2nd ed). New York: Psychological Press. [Full text] [Back to text]

Mayer, J.,Caruso, D. R., \& Salovey,P . (2000). Selecting a measure of emotional intelligence: the case for ability scales. In R. Bar-On,\& J.D. A. Parker (Eds.), The handbook of emotional intelligence (pp. 320 342). San Francisco: Jossey-Bass Inc. [Full text] [Back to text]

Mayer, J. D., Salovey, P., \& Caruso (2000). Models of emotional intelligence. In R. J. Sternberg (Ed.), Handbook of intelligence (pp. 396-420). New York: Cambridge. [Full text] [Back to text]

Mayer, J., \& Salovey, P. (1997). What is emotional intelligence? In $P$. Salovey, \& D. Sluyter (Eds.), Emotional development and emotional intelligence: implications for educators (pp. 331). New York: Basicbooks. [Full text] [Back to text]

Neophytou, L. (2009). The relation between emotional intelligence and teachers' beliefs and their effect on effectiveness and quality of teaching. Unpublished doctoral dissertation. University of Cyprus, 2009, ISBN: 978-9963-671-85-4. [Back to text]

Neophytou, L. (in press). Examining the reliability and validity of the Greek version of the MSCEIT-V2. Proceedings of the 7th Panhellenic conference of the Hellenic Pedagogical Society. [Back to text]

Newsome,S., Day, A. L., \& Catano,V. M. (2000). Assessing the predictive validity of emotional intelligence. Personality and Individual 
Differences, 29, 1005-1016. [Full text] [Back to text]

Palmer, B.R., Manocha, R.,Gignaca, \& Stougha,C. (2003). Examining the factor structure of the Bar-On Emotional Quotient Inventory with an Australian general population sample. Personality and Individual Differences, 35, 1191-1210. [Full text] [Back to text]

Petrides, K. V., \& Furnham, A. (2001). Trait emotional intelligence: psychometric investigation with reference to established trait taxonomies. European Journal or Personality, 15, 425-448. [Full text] [Back to text]

Petrides, K.,\& Furnham,A. (2000). On the dimensional structure of emotional intelligence. Personality and Individual Differences, 29, 313320. [Full text] [Back to text]

Plake, B. S., \& Impara, J. C. (Eds.). (1999). Supplement to the thirteenth mental measurement yearbook. Lincoln, NE: Buros
Institute for Mental Measurement. [Abstract] [Back to text]

Raykov, T. (1997). Estimation of composite reliability for congeneric measures. Applied Psychological Measurement, 21(2), 173-184. [Full text] [Back to text]

Raykov, T. (1998). Coefficient alpha and composite reliability with interrelated non-homogeneous items. Applied Psychological Measurement, 22(4), 375-385. [Full text] [Back to text]

Raykov, T. (2001). Bias of coefficient alpha for fixed congeneric measures with correlated errors. Applied Psychological Measurement, 25(1), pp. 69-76. [Full text] [Back to text]

Hill,T.\& Lewicki, P. (2006). Statistics: methods and applications : $a$ comprehensive reference for science, industry, and data mining. Tulsa, OK: StatSoft, Inc. [Full text] [Back to text]

Tossman, D. (1999). EQ: Value or vogue? Management, 46(5), 34. [Abstract] [Back to text] 